\title{
Desenvolvimento de uma Extensão Telefônica Remota utilizando a Rede de Telefonia Celular GSM
}

\author{
Title: Development of a remote extension phone using the GSM cellular network
}

Társis Cavalcanti Siqueira

Escola Politécnica de Pernambuco

Universidade de Pernambuco

50.720-001 - Recife, Brasil

tarsiscs@gmail.com

\author{
Sérgio Campello Oliveira \\ Escola Politécnica de Pernambuco \\ Universidade de Pernambuco \\ 50.720-001 - Recife, Brasil \\ scampello@ecomp.poli.br
}

Resumo funcionalidade de atender ligações remotamente, originadas para um telefone fixo, é um ser-
viço oferecido por operadoras de telefonia no Brasil. Esse serviço é disponibilizado através da
assinatura e pagamento de mensalidades e custos das ligações redirecionadas. Essas cobranças
e a limitação em apenas receber chamadas, não sendo possivel utilizar a linha telefônica fixa
para, a partir dela, realizar uma chamada utilizando um ramal remoto, dificultam o uso dessas
soluções. Esse artigo descreve a criação de um sistema embarcado que utiliza a tecnologia da
rede de telefonia celular GSM para implementar uma interface capaz de transferir ligações
recebidas na linha fixa para um número remoto, bem como originar ligações remotamente atra-
vés da linha telefônica conectada ao sistema. Foi utilizado o Arduino Uno com um Shield GSM,
bem como um hardware auxiliar projetado. Como se trata de um módulo físico, é possível utili-
zar o sistema proposto em redes de telefonia empresariais, nas quais não seria possivel contra-
tar serviços de operadoras de telefonia para transferir as ligações dos ramais. Os testes mostra-
ram que o sistema se comporta muito bem, com ligações de boa qualidade e baixo custo. Por
utilizar a rede GSM, várias outras implementaçôes podem ser realizadas, tais como a interface
com sistemas de segurança e automação predial.

Palavras-Chave: Sistema embarcado, Arduino, Rede GSM, Circuito Telefônico, Automação predial

\begin{abstract}
The functionality to answer calls remotely, originated for a landline, is a service offered by telephone operators in Brazil. This service is available through the subscription and payment of fees and costs of the redirected calls. These charges and the limitation of only receive calls, not being possible to use the phone line for, from it, make a call using a remote extension, hinder the use of these solutions. This article describes the creation of an embedded system using the GSM cellular network technology to implement an interface capable to transferring incoming calls on a landline to a remote number, as well as to originate calls remotely through the line connected to the system. To do that, an Arduino Uno was used with a GSM shield and a designed auxiliary hardware. As it is a physical module, you can use the proposed system in enterprise telephone networks, where would not be possible to hire telephone operators services to transfer the calls from extensions. The tests showed that the system behaves very well, with good quality and low cost calls. Given that the system uses the GSM network, several other implementations may be performed, such as interfacing with security and building automation systems.
\end{abstract}

Keywords: Embedded System, Arduino, GSM Network, Telephonic Circuit, Building automation 


\section{Introdução}

Os sistemas de extensões em uma instalação telefônica são limitados pela infraestrutura local. Quando realizadas por cabos ou através de aparelhos sem-fio, as extensões atenderão apenas às dependências do edifício comercial ou residencial. Havendo a necessidade do usuário atender às chamadas do seu ramal estando fora das dependências da empresa ou fora da sua residência, ele poderá contratar serviços de transferência de ligação oferecidos pelas operadoras de telefonia. Esses serviços geram custos adicionais de contratação [1] e tarifam as ligações transferidas para o número escolhido [2]. Além das despesas geradas pela utilização desse serviço, ele não funciona como uma extensão telefônica, ou seja, não é possível realizar a operação inversa, utilizando remotamente a linha fixa, ou ramal, para realizar ligações a partir dela.

O projeto proposto implementa uma extensão telefônica remota de uma linha fixa, ou ramal. Utiliza a rede celular GSM, possibilitando a implementação de um sistema de ramal remoto, a um baixo custo, selecionando uma operadora de telefonia celular que tenha melhores tarifas, e com a funcionalidade de receber e originar chamadas a partir da linha fixa.

Um sistema desse tipo poderia ter, ainda, diversas outras aplicações, como acionamentos remotos, sendo utilizado na automatização de tarefas e controle de cargas elétricas em residências ou edifícios inteligentes. Por exemplo, interpretando mensagens SMS, ou tons DTMF recebidos, pode-se acionar lâmpadas, aparelhos de ar condicionado ou realizar a abertura de uma fechadura eletrônica.

O uso em aplicações voltadas a sistemas de segurança, tais como a captação de áudio para escuta e monitoramento de sensores é também muito promissor. Essa utilização possibilita o desenvolvimento de sistemas que podem, por exemplo, verificar o estado de um sensor e enviar mensagens ou realizar ligações através da linha telefônica fixa, que é mais confiável que a rede de telefonia celular. Pode, ainda, abrir um canal de áudio a partir da linha telefônica para a comunicação ou escuta em casos de emergência.

O objetivo desse trabalho é desenvolver um sistema embarcado capaz de utilizar a rede de telefonia celular GSM, e implementar uma extensão através dessa rede. A Figura 1 mostra um diagrama de blocos do sistema. A extensão GSM detecta a chegada de uma chamada na linha telefônica, à qual esta conectada, e automaticamente liga para um telefone remoto cadastrado, buscando realizar a transferência dessa ligação. Da mesma forma, o sistema possibilita a utilização da linha telefônica a partir do telefone remoto cadastrado. A extensão GSM poderá receber uma ligação originada pelo telefone remoto cadastrado, atender essa ligação e interconectá-lo à linha telefônica e, através de um circuito de discagem, realizar ligações através da linha telefônica, como se essa ligação estivesse sendo originada pela extensão fixa.

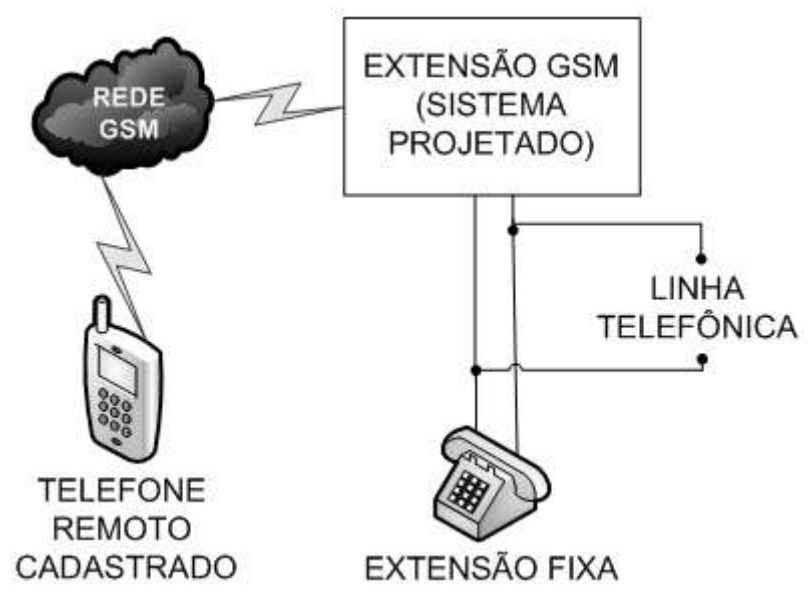

Figura 1 : Diagrama de blocos do sistema

Na Seção 2 apresenta-se os principais elementos necessários para a construção do sistema. Na Seção 3 apresenta-se o projeto desenvolvido, tanto a parte do hardware como do firmware. Na Seção 4, são exibidos os testes e os resultados obtidos. Por fim, a Seção 5 apresenta as conclusões do artigo e discute trabalhos futuros.

\section{Fundamentos}

Para o desenvolvimento do sistema, alguns conceitos e ferramentas utilizadas são fundamentais. Assim, foram destacados a linha telefônica, o DTMF, o circuito telefônico, o Arduino, os comandos AT e o Shield GSM.

\subsection{A linha telefônica}

A ligação entre as centrais telefônicas e os assinantes é denominada linha telefônica. Normalmente é realizada por condutores metálicos e transporta, além do áudio das ligações, alguns sinais utilizados nas chamadas telefônicas. Como exemplo, é possível citar o tom de linha, o tom de discagem, o tom de ocupado e o sinal de chamada.

Os níveis de tensão elétrica da linha telefônica devem ser conhecidos para a correta alimentação e proteção dos circuitos telefônicos. Quando o aparelho telefônico está desligado (no gancho), a tensão medida entre os terminais da linha telefônica é de 48VDC. Ao ser retirado do gancho, a tensão medida nos terminais da linha telefônica é de 9VDC, podendo variar entre 6VDC a 14VDC, de acordo com o cumprimento da linha telefônica [3]. 
Quando a central telefônica recebe uma chamada, o sinal de chamada é enviado ao assinante através da linha telefônica. Esse sinal possui um ciclo completo de $5000 \pm$ $500 \mathrm{~ms}$. O período de tom, no qual é enviado uma onda senoidal de tensão nominal de 70Vef [3] e frequência de $25 \pm 2,5 \mathrm{~Hz}$, é igual a $1000 \pm 100 \mathrm{~ms}$, e o período de silêncio é de $4000 \pm 400 \mathrm{~ms}$ [4].

O conhecimento das características do sinal de chamada é de fundamental importância para o preciso tratamento do sinal e devida interpretação do recebimento de uma chamada telefônica.

\subsection{DTMF}

Em aparelhos telefônicos antigos, a ligação telefônica era originada através de pulsos de discagem, implementados por um disco de discagem rotativo, que possuía dez furos igualmente espaçados. O número de pulsos de discagem era determinado pela distância que o disco era rotacionado antes de ser solto [5].

A maioria dos aparelhos telefônicos modernos utilizam um método chamado DTMF, sigla em inglês de Dual-Tone Multi-Frequency. Os tons de dupla frequência são gerados ao pressionar uma tecla do teclado numérico responsável pela discagem. Um tom de baixa frequência está associado a cada linha, assim como um tom de alta frequência está associado a cada coluna. As frequências associadas a cada tecla [5] podem ser visualizadas na Figura 2. Ao pressionar a tecla 5, por exemplo, será gerado um tom de $770 \mathrm{~Hz}$ e um tom de $1336 \mathrm{~Hz}$. Pelo uso do método de tons duplos, é possível criar 12 combinações únicas, utilizando apenas 7 tons, quando um teclado numérico de 12 posições é utilizado.

O DTMF foi criado utilizando frequências escolhidas para que os circuitos de processamento, chamados de circuitos de recebimento de dígito, não os confundam com outros tons que podem ocorrer na linha telefônica [5].

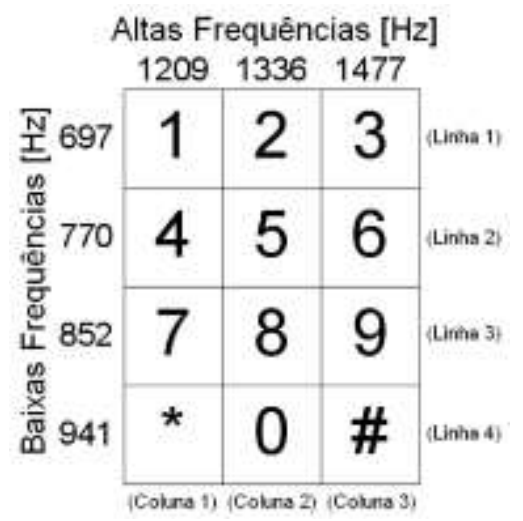

Figura 2 : Teclado DTMF
Circuitos integrados foram desenvolvidos para a geração dos tons DTMF. No projeto objeto desse artigo, foi utilizado o circuito integrado HT9200A, que recebe, via comunicação serial, o digito que deve ser discado e gera o tom correspondente em sua saída. Dessa forma, é possível gerar os tons necessários para a discagem sem a necessidade de implementação de um teclado numérico, sendo esse circuito integrado de grande utilidade para a implementação de discagem DTMF em sistemas microcontrolados.

\subsection{Circuito telefônico}

A Figura 3 mostra o diagrama de blocos de um aparelho telefônico básico.

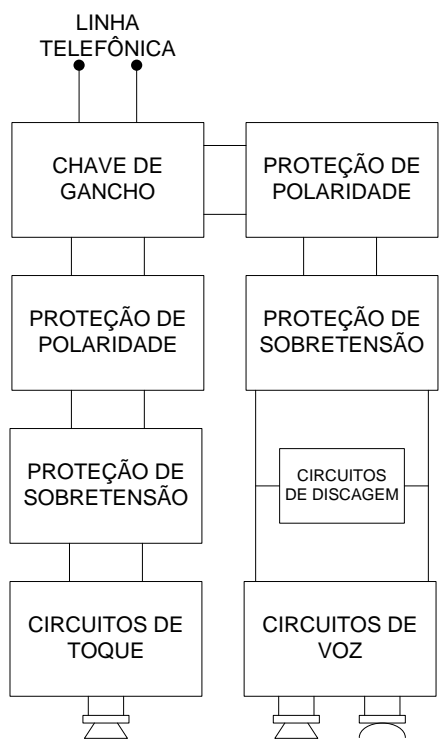

Figura 3 : Aparelho telefônico básico

A chave de gancho é responsável por manter os circuitos de voz desligados e os circuitos de toque ligados, enquanto o aparelho telefônico está no gancho. Ao receber uma chamada, os circuitos de toque normalmente emitem um som, alertando o usuário que uma chamada está sendo recebida. Ao retirar o telefone do gancho, a chave de gancho inverte suas ligações, desconectando a linha telefônica dos circuitos de toque, conectando aos circuitos de voz, possibilitando a comunicação na chamada.

Os módulos de proteção de polaridade normalmente utilizam o método da ponte retificadora, tendo em vista que a polaridade da tensão de saída de uma ponte retificadora é sempre a mesma, independente da polaridade presente na tensão de entrada. Esses módulos são necessários, pois a polaridade é crítica para circuitos eletrônicos, uma vez que com uma polaridade reversa ele podem não operar corretamente ou até serem danificados [5]. 
Os blocos de proteção de sobretensão são responsáveis pela proteção dos circuitos eletrônicos, que utilizam transistores de pequeno sinal e circuitos integrados que são facilmente danificados por transientes de sobretensão que podem surgir na linha. Para a implementação desta proteção, um ou mais diodos zener são adicionados através da linha [5]. Quando a tensão de entrada excede o valor da tensão de ruptura do diodo zener, ele conduz e mantém a tensão de entrada do circuito eletrônico igual à tensão de ruptura do diodo escolhido.

Os circuitos de toque são responsáveis por, ao receberem o sinal de chamada, gerar alertas aos usuários.

Circuitos de discagem geram os sinais necessários na linha telefônica referentes ao número de destino desejado, possibilitando que o usuário escolha um número de destino e o chame, estabelecendo uma ligação telefônica. Normalmente são gerados tons DTMF.

Finalmente, após a chamada ser respondida, os circuitos de voz implementam a interface de áudio para que os interlocutores possam ter sua voz captada e ouvida do outro lado da linha telefônica. De forma resumida, esses circuitos captam os sinais de áudio da linha telefônica, através de filtros que removem a componente DC do sinal, o amplificam e disponibilizam para a alimentação de um alto-falante. O caminho oposto ocorre com a captação da voz, que é realizada por um microfone, normalmente de eletreto, sendo esse sinal amplificado e injetado na linha telefônica.

Muitos outros fatores e particularidades estão envolvidos nos circuitos de voz, tais como o efeito local, responsável por fazer com que o usuário escute sua própria voz, captada pelo microfone do seu aparelho telefônico, refletida no alto-falante do próprio aparelho, bem como as técnicas utilizadas para controlar esse efeito.

\subsection{Arduino}

O Arduino é uma placa de desenvolvimento, que pode ser programada para processar entradas e saídas e prover comunicação com componentes externos que são a ele conectados [6].

A escolha do Arduino para o projeto foi baseada na facilidade de prototipação e na grande variedade de material de estudo disponível. Essa facilidade se deve ao fato de que o software e hardware do Arduino são, ambos, de código aberto. Isso significa que o código, esquemas, projetos e todo o material disponibilizado pode ser utilizado por qualquer pessoa, para realizar o projeto que desejar. A placa escolhida para a realização do projeto foi o Arduino Uno.

\subsection{Comandos AT}

Os modems são módulos amplamente divulgados, que possuem ligação com a rede telefônica, e cuja interface com microcontroladores e computadores é realizada através de normas padrão. O padrão $\mathrm{AT}$ é uma linguagem de linha de comandos.

Os principais comandos utilizados no projeto podem ser visualizados na Tabela 1 .

\begin{tabular}{|l|l|}
\hline \multicolumn{1}{|c|}{ Comando } & \multicolumn{2}{c|}{ Função } \\
\hline AT & Exibe o status \\
\hline ATD NÚMERO; & Disca para o NÚMERO informado \\
\hline ATH & Encerra a chamada \\
\hline ATA & Atende a chamada \\
\hline AT+CHFA $=$ & Configura o canal de áudio utilizado \\
\hline AT+CHF $=$ & Habilita/Desabilita o modo handfree \\
\hline AT+ECHO $=$ & Configura a supressão de eco \\
\hline AT+SIDET $=$ & Habilita/Desabilita o efeito local \\
\hline AT+CLVL $=$ & Configura o volume de saída de áudio \\
\hline AT+CMIC $=$ & Configura o ganho de entrada de áudio \\
\hline AT+DDET $=$ & Habilita/Desabilita a decodificação DTMF \\
\hline
\end{tabular}

Tabela 1 : Comandos AT

Cada comando é formado por três elementos: o prefixo, o corpo do comando e o caractere de terminação.

O prefixo consiste nos caracteres "AT". O corpo do comando é formado por caracteres individuais, ligados à funções específicas que se deseje executar. O caractere de terminação é o " $<\mathrm{CR}>$ " [8].

\subsection{Shield GSM}

O Arduino pode ser expandido utilizando Shields, que são placas de circuito contendo outros dispositivos, tais como receptores GPS, Displays LCD, módulos Ethernet, dentre muitos outros [6].

Para o projeto em questão, foi empregado o Shield GSM do fabricante TinySine, o qual é exibido na Figura 4 , com seus principais componentes destacados.

O Shield GSM, provê um caminho para o uso da rede de telefonia celular GSM para receber e enviar dados remotamente.

A troca de dados pode ser executada por uma dessas três formas:

- Mensagens de texto (SMS);

- Ligações telefônicas (Áudio);

- Serviço GPRS.

O Shield GSM escolhido é compatível com o Arduino Uno, é configurado e controlado via comunicação serial 
UART, utilizando simples comandos AT e é baseado no módulo SIM900 da SIMCOM. Esse módulo possui funções muito importantes, como o controle do ganho de entrada e volume de saída, supressão de eco e decodificação DTMF. Além das características de comunicação, o Shield GSM ainda possui 12 pinos de E/S, 2 pinos PWM e um conversor analógico-digital [9].

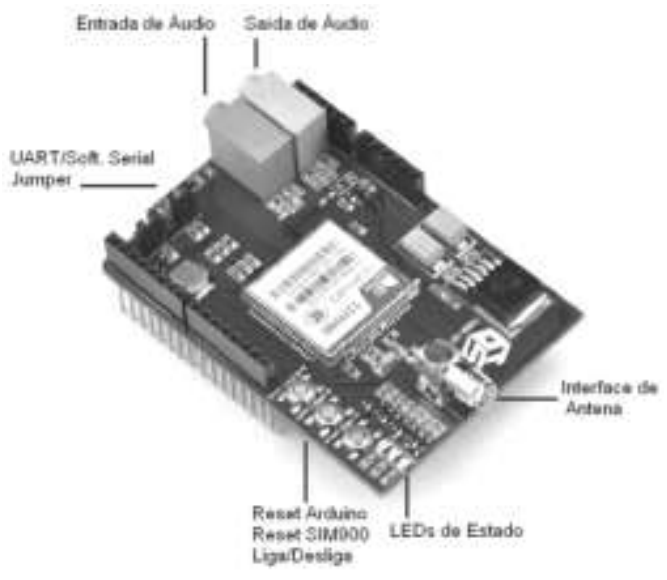

Figura 4: Shield GSM.

\section{Projetos de hardware e firmware}

Para o desenvolvimento do hardware, foram utilizados o Arduino Uno, o Shield GSM e um circuito eletrônico projetado, conforme diagrama da Figura 5.

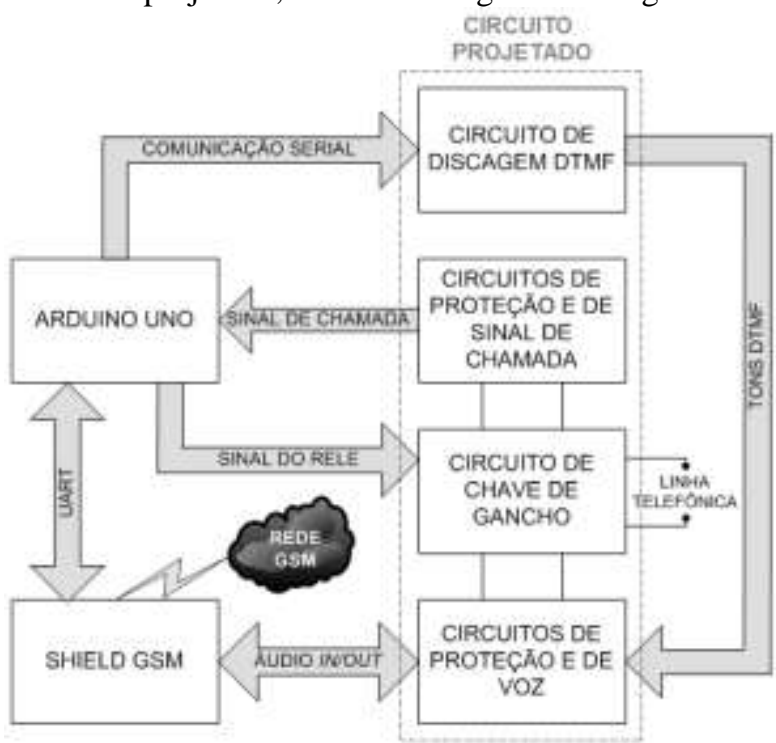

Figura 5: Diagrama de blocos do projeto.

Este circuito é composto por quatro partes. A primeira é o circuito responsável pelo acionamento da linha (chave de gancho). A segunda é o circuito de voz, com proteção de polaridade e sobretensão. A terceira é o circuito de filtragem e tratamento do sinal de chamada e a quarta é o circuito discador DTMF.

Para o desenvolvimento do firmware e a programação do Arduino, foi utilizada a IDE em código aberto disponibilizada, que possui todas as funções necessárias para a edição e compilação do firmware e a gravação da memória flash do Arduino.

A IDE utilizada possui a funcionalidade de terminal, dessa forma, foi possível acompanhar a execução do firmware e funcionamento do sistema por meio de informações visíveis na tela do computador.

A montagem foi realizada em protoboard, mostrada na Figura 6.

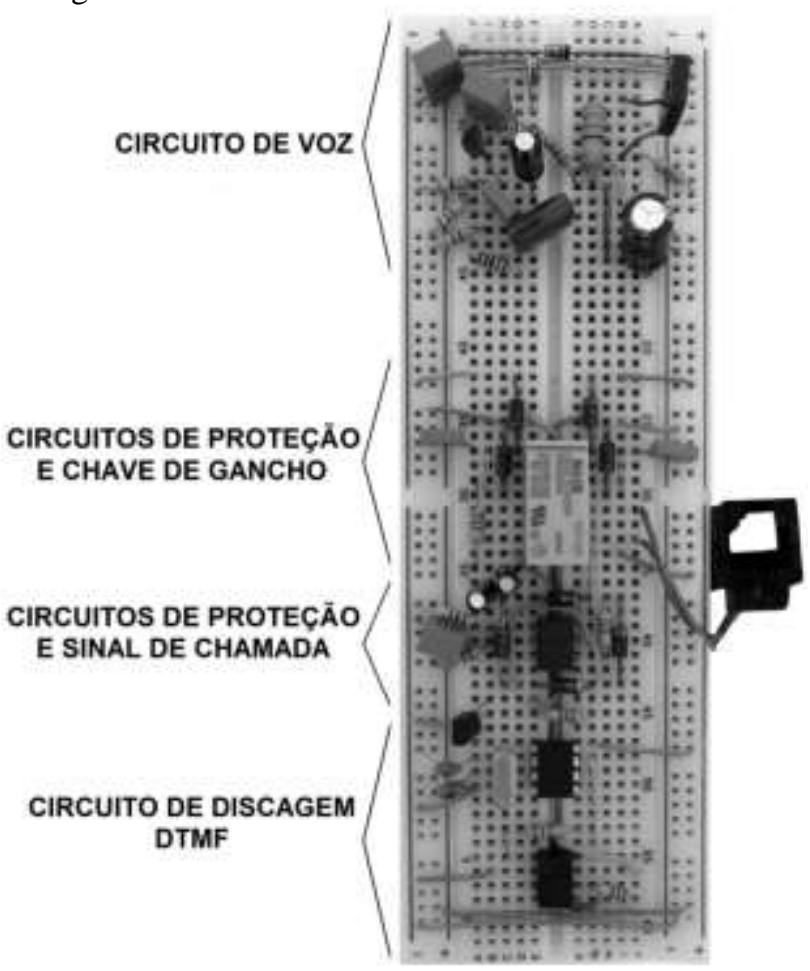

Figura 6: Circuitos montados em protoboard.

O conjunto Arduino e Shield GSM foi interconectado ao circuito projetado, proporcionando as funcionalidades de receber e realizar chamadas na linha telefônica através de um telefone remoto cadastrado.

A interface dos circuitos projetados, conectado à linha telefônica, com o arduíno, foi implementada através de isoladores ópticos, proporcionando total isolamento elétrico, evitando que circuitos mais sensiveis pudessem ser danificados por possíveis sinais provenientes da linha telefônica.

Não foi necessário implementar um hardware para a adequação dos níveis dos sinais de áudio de entrada e saída, tendo em vista que foi possível alterar o ganho de entrada e volume de saída do Shield GSM através de comandos AT. 


\subsection{Fluxograma do código}

O código de controle do sistema, cujo o fluxograma está mostrado na Figura 7, foi desenvolvido em linguagem C. Foi utilizada a estrutura switch-case para a implementação de uma máquina de estados. Esta técnica facilitou a programação e a verificação das corretas mudanças de estado através de informações enviadas para o terminal do computador.

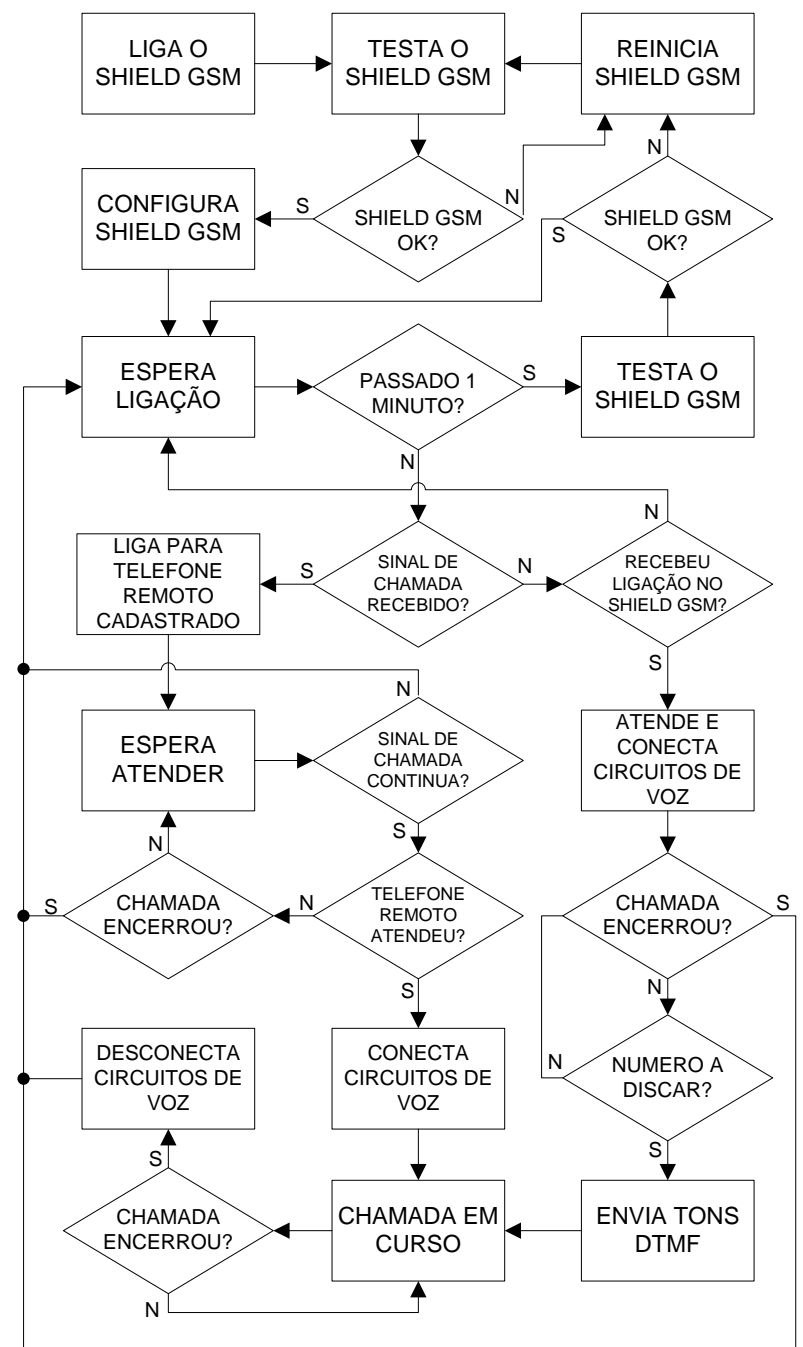

Figura 7: Fluxograma do código.

O código inicia ligando o Shield GSM e continua para um loop que testa se a comunicação com o mesmo está ocorrendo normalmente e se existe sinal da operadora GSM. Sendo o teste bem sucedido, o código segue com a configuração do Shield GSM. Depois, aguarda a chegada de uma ligação, seja o sinal de chamada na linha telefônica ou uma chamada proveniente do telefone remoto cadastrado para o Shield GSM. Durante a espera por ligações, a cada 1 minuto o Shield GSM é testado e, caso seja apresentado algum problema, o mesmo é reiniciado e reconfigurado.

Sendo recebido o sinal de chamada na linha telefônica, é realizada uma chamada para o telefone remoto cadastrado visando a transferência da ligação. $\mathrm{O}$ código realiza o tratamento para saber se o sinal de chamada continua sendo enviado para a linha telefônica e se o telefone remoto atendeu. Uma vez que o telefone remoto cadastrado atende a ligação, os circuitos de voz são conectados e a ligação é efetivamente transferida.

Com a chamada em curso, o código sempre testa se a chamada foi encerrada para desconectar os circuitos de voz e guardar uma nova ligação.

Em uma segunda situação, caso seja recebida uma chamada proveniente do telefone remoto cadastrado para o Shield GSM, a chamada é atendida e os circuitos de voz são conectados.

Um loop é executado para saber se foi digitado algum número telefônico no telefone remoto cadastrado. Caso um número telefônico seja digitado, os tons DTMF são enviados e a chamada continua em curso, sendo testado, também, se houve o encerramento da chamada para a desconexão dos circuitos de voz e a espera de novas ligações.

\subsection{Circuitos elétricos}

O esquema dos circuitos eletrônicos desenvolvidos também foi dividido em quatro partes: circuito de chave de gancho, circuitos de voz, circuitos de sinal de chamada e circuitos de discagem DTMF.

Os circuitos eletrônicos, assim como o Arduino, são alimentados por uma fonte externa regulada de 5 volts, que não é apresentada nos esquemas.

A Figura 8 mostra o circuito que realiza a função da chave de gancho. $\mathrm{O}$ acionamento é realizado pelo Arduino através do transistor $\mathrm{T} 1$, que, ao ser alimentado, opera em sua região de saturação e aciona o rele. $\mathrm{O}$ resistor R1 limita a corrente de base do transistor T1.

Os terminais RL1 e RL2 conectam a linha telefônica aos circuitos de sinal de chamada e os terminais RL3 e RL4 conectam a linha telefônica aos circuitos de voz.

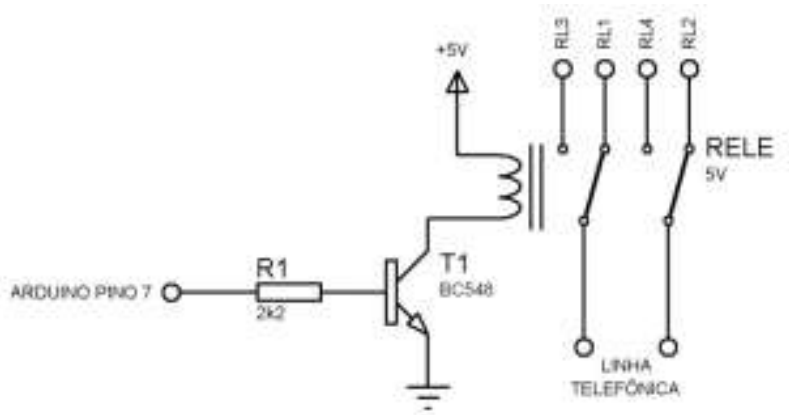

Figura 8: Rele com função de chave de gancho.

Os circuitos de voz, com proteção de polaridade e sobrecorrente são mostrados na Figura 9. 


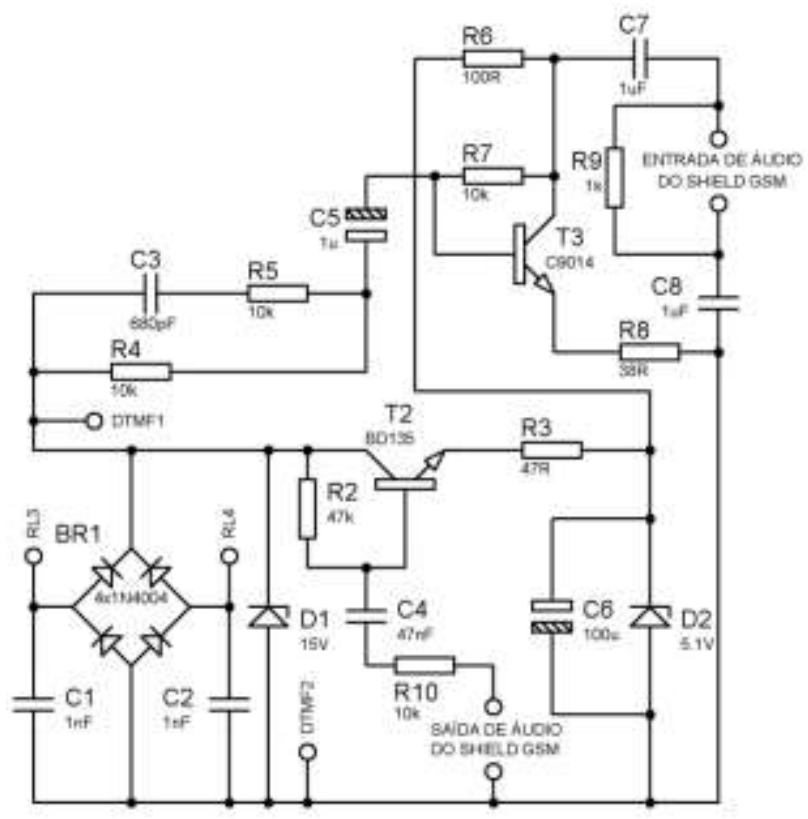

Figura 9: Circuitos de voz.

A ponte retificadora BR1 protege o circuito contra a inversão da polaridade, enquanto os capacitores $\mathrm{C} 1$ e C2 filtram possíveis ruídos.

O diodo zener D1 na saída da ponte retificadora é utilizado para a proteção contra sobretensão, limitando a tensão do circuito em $15 \mathrm{~V}$, que é a sua tensão de ruptura. $\mathrm{O}$ conjunto formado pelo transistor $\mathrm{T} 2$, resistores $\mathrm{R} 2 \mathrm{e}$ $\mathrm{R} 3$, diodo zener D2 e capacitor C6 formam um regulador de tensão, fornecendo aproximadamente 5 volts.

Os sinais de voz são acoplados ao estagio de amplificação de áudio construído com o transistor T3, resistores R4, R5, R6, R7 e R8 e capacitores C3 e C5. O sinal amplificado no coletor do transistor T3 é conectado à entrada de áudio do Shield GSM através do resistor R9 do capacitores C7 e C8, conforme o modelo de acomplamento para uma entrada de linha diferencial no Shield GSM [10].

A saída de áudio do Shield GSM é conectada à base do transistor T2 através do resistor R10 e do capacitor C4 e, depois de amplificado pelo transistor T2, o sinal de áudio é acoplado à linha telefônica através da ponte retificadora BR1.

A Figura 10 apresenta o circuito de filtragem e tratamento do sinal de chamada. A linha telefônica é conectada à ponte retificadora BR2 através do resistor R11 e dos capacitores $\mathrm{C} 9$ e C10, que removem a componente DC. Após o sinal de toque ser retificado, ele alimenta o diodo emissor de luz do acoplador óptico U1, através do resistor R12, utilizado para limitar a corrente.

O capacitor C11 é carregado através do resistor R14 e quando o fototransistor do acoplador óptico conduz a corrente do coletor para o emissor, o capacitor é descarregado através do resistor R13. O sinal gerado no coletor do fototransistor é conectado ao pino 10 do Arduino para a detecção do sinal chamada na linha telefônica.

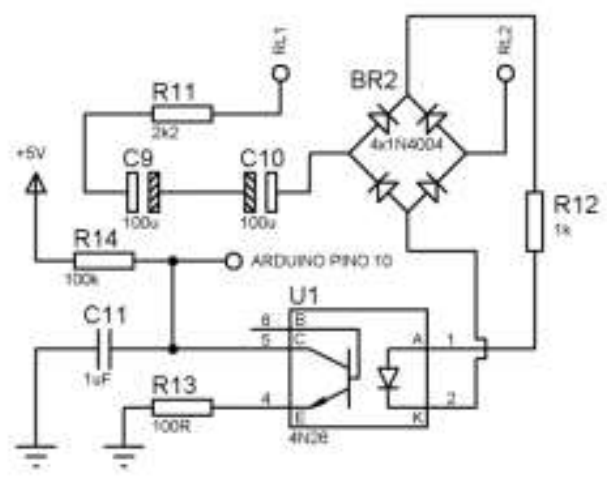

Figura 10: Circuitos do sinal de chamada.

O circuito de discagem DTMF é exibido na Figura 11.

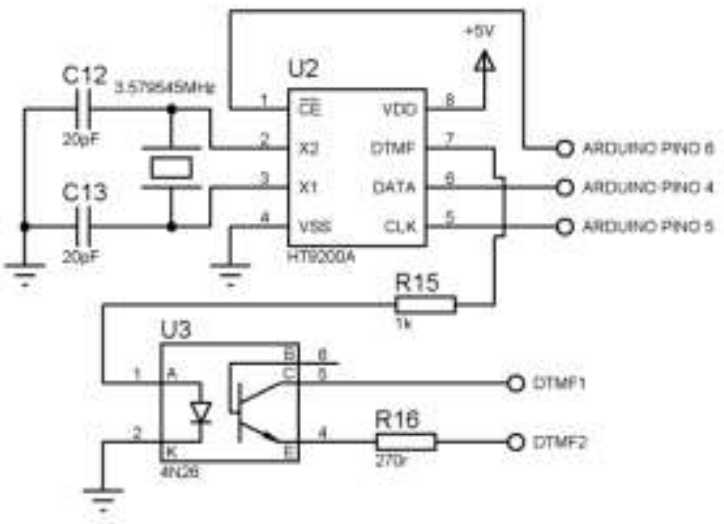

Figura 11: Circuitos de discagem DTMF

O circuito integrado U2 é um HT9200A, responsável por gerar os tons DTMF.

Ele recebe a informação através de uma comunicação serial, realizada pelos pinos 6, 5 e 4 do Arduino. Ao receber a informação do tom a ser gerado, o circuito integrado gera o tom DTMF na sua saída, através do seu pino 7. Esse tom é injetado na linha telefônica por meio do acoplador óptico U3, que isola eletricamente o circuito do Arduino do circuito telefônico.

Os resistores R15 e R16 são limitadores de corrente para o correto funcionamento do circuito.

Os capacitores $\mathrm{C} 12$ e $\mathrm{C} 13$ e o cristal de quartzo são componentes externos necessários para o funcionamento do circuito integrado $\mathrm{U} 2$, os quais tem os seus valores definidos pelo datasheet do fabricante do HT9200A [11].

\section{Testes}

Realizou-se testes para a verificação da correta das formas de onda geradas pelo sinal de chamada, da qualidade do áudio e do desvio e discagem das chamadas. 


\subsection{Formas de onda}

A Figura 12 expõe as formas de onda geradas quando a linha telefônica recebe o sinal de chamada. A Figura 12a mostra o tom do sinal de chamada, que é uma onda senoidal com frequência de $25 \mathrm{~Hz} \pm 2,5 \mathrm{~Hz}$, medido no coletor do fototransistor do acoplador óptico U1, caso o capacitor $\mathrm{C} 11$ esteja desconectado. Para a interpretação deste sinal seria necessário analisar a forma de onda com um conversor analógico digital. Buscando adequar o sinal recebido para realizar uma análise mais simples, apenas digital, foi adicionado o capacitor $\mathrm{C} 11$. Como o resistor de carga do capacitor C11 é mil vezes maior que o de descarga, a descarga ocorre em um tempo muito menor que a carga, gerando a forma de onda apresentada na Figura 12b. O sinal de chamada visto por um maior período é apresentado na Figura 12c, que ratifica o período de 5 segundos, sendo 1 segundo de tom e 4 segundos de silêncio.

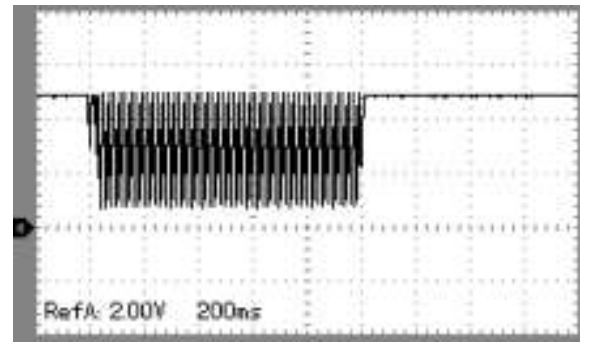

(a)

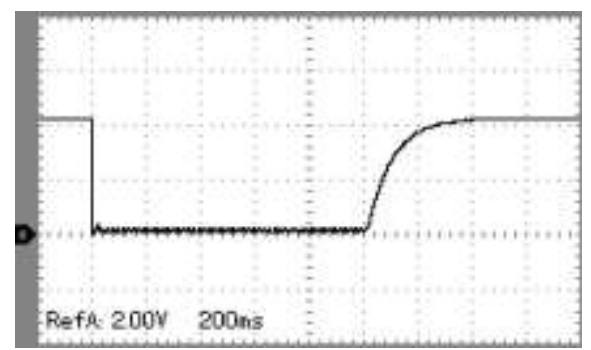

(b)

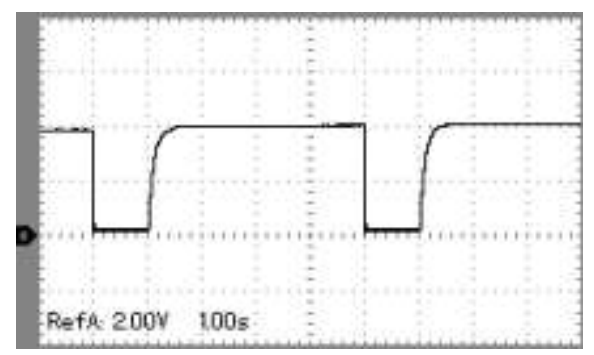

(c)

Figura 12: Formas de onda geradas pelo sinal de chamada (a) sem o capacitor $\mathrm{C} 11$; (b) com o capacitor $\mathrm{C} 11$; (c) visto por um maior período.

No decorrer dos testes, o sinal gerado pelo circuito do sinal de chamada apresentou pequenos pulsos espúrios, mostrados na Figura 13. Esses pulsos faziam com que o sistema interpretasse que a linha fixa estava recebendo uma chamada.

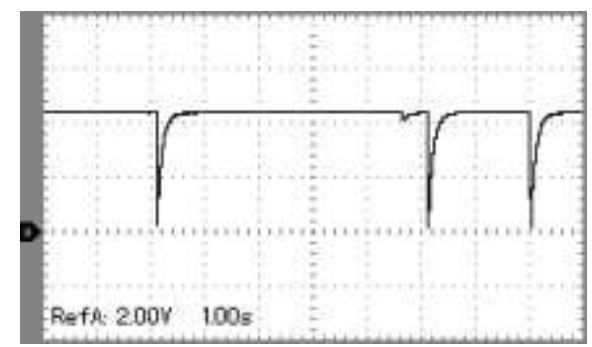

Figura 13: Pulsos espúrios gerados.

Por conta desse comportamento, o sinal de chamada recebeu um tratamento no código para realizar um debounce, que consiste realizar um novo teste $500 \mathrm{~ms}$ após o recebimento do pulso, garantindo que a interpretação do recebimento de chamada não ocorresse no recebimento de pulsos espúrios transitórios.

\subsection{Teste de áudio}

A metodologia utilizada para testar a qualidade do áudio nas ligações foi uma pesquisa, realizada com dez usuários, que não sabiam que estavam recebendo uma ligação de um sistema em teste, solicitando que os mesmos informassem o grau de satisfação com a qualidade do áudio da ligação.

Foram utilizados quatro níveis: totalmente insatisfeito, insatisfeito, satisfeito e totalmente satisfeito.

Cada usuário recebeu duas ligações, com duração mínima de 20 segundos. O gráfico da Figura 14 apresenta os resultados obtidos.

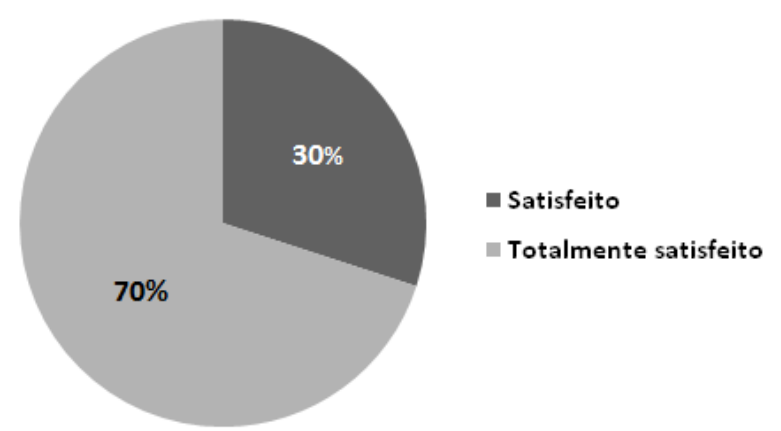

Figura 14: Resultado da pesquisa de satisfação com o áudio da ligação

\subsection{Testes de ligação}

Para testar o correto funcionamento das ligações, foram realizadas $10(\mathrm{dez})$ chamadas para a linha fixa, verificando se a chamada seria corretamente direcionada pelo sistema projetado para o número cadastrado. Todas as chamadas foram devidamente encaminhadas.

Da mesma forma, o ramal remoto realizou 10 (dez) ligações para o sistema projetado, visando testar se a 
chamada seria corretamente atendida e se a linha fixa seria interconectada com o ramal remoto. As 10 (dez) ligações foram atendidas e interconectadas com a linha fixa corretamente.

Por fim, nas 10 (dez) ligações originadas pelo ramal remoto e atendidas pelo sistema projetado, foram realizadas ligações para verificar o correto funcionamento do circuito de discagem DTMF. Em todos os casos, também, o número desejado foi corretamente discado.

\section{Conclusões e trabalhos futuros}

Esse artigo propôs o desenvolvimento de um sistema embarcado que utiliza o Arduino, um Shield GSM e um hardware projetado e desenvolvido para realizar a interface do sistema com uma linha telefônica fixa. O sistema foi utilizado para realizar e receber chamadas telefônicas através de uma linha telefônica fixa, funcionando como uma extensão telefônica remota.

Os testes de ligação e recepção de ligações foram realizados com sucesso, possibilitando a correta realização de ligações através do sistema embarcado, com boa qualidade de áudio e de ligação, qualidade essa aferida por uma pesquisa de satisfação realizada com dez usuários com os quais foram efetuadas chamadas a partir do sistema desenvolvido.

A este trabalho poderá ser dada continuidade, melhorando e implementando novas funcionalidades.

A incorporação de um detector de tom de ocupado, visando o desligamento automático da chamada transferida da linha telefônica para o telefone remoto cadastrado, caso a chamada seja encerrada pelo usuário que originou a ligação para a linha telefônica, seria uma característica importante a ser acrescentada ao sistema.

Podem ser executados estudos para expansão do escopo de atuação do sistema, buscando novas áreas de atuação, utilizando a tecnologia já estudada e projetada de utilização da rede de telefonia GSM. Isso incluiria módulos para a interface com sistemas de segurança, alarme e sistemas de CFTV e automação residencial e predial.

\section{Referências}

[1] GVT. Siga-me Nacional. Disponivel em: $<$ https://goo.gl/OQArrx>. Acesso em: 6 Janeiro 2016.

[2] OI. Guia Siga-me. Disponivel em: $<$ http://goo.gl/C5ZT8D $>$. Acesso em: 5 Janeiro 2016.

[3] TATEOKI, G. T. Informações básicas sobre telefonia. Disponivel em: $<\mathrm{http}: / /$ goo.gl/n86vYX $>$. Acesso em: 11
Dezembro 2015.

[4] ALCANTARA, P. Apostila de Telefonia.

[5] BIGELOW, S. J.; CARR, J. J.; WINDER, S. Understanding Telephone Electronics. $4^{\mathrm{a}}$ Edição. ed. Woburn: Newnes, 2001.

[6] MCROBERTS, M. Beginning Arduino. New York: apress, 2010.

[7] ARDUINO. Products. Disponivel em: $<$ https://goo.gl/LUBeIG $>$. Acesso em: 2 Fevereiro 2016.

[8] SIMCOM. SIM900 AT Commands Manual. Disponivel em: $<$ http://goo.gl/3xpcct $>$. Acesso em: 10 Novembro 2015.

[9] TINYSINE. Datasheet Shield GSM. Disponivel em: <http://goo.gl/osVuEM>. Acesso em: 7 Outubro 2015.

[10] SIMCOM. AN SIM900 Audio Line-in input. Disponivel em: <http://goo.gl/p43Dat>. Acesso em: 17 Novembro 2015.

[11] HOLTEK. Datasheet HT9200. Disponivel em: <http://goo.gl/PtVjUF>. Acesso em: 4 Janeiro 2016.

[12] ANATEL. Documentos. Disponivel em: $<$ http://goo.gl/KvolGC $>$. Acesso em: 28 Janeiro 2016. 